\title{
Electrochemical Deposition and Optimization of Thermoelectric Nanostructured Bismuth Telluride Thick Films
}

\author{
Hesham M. A. Soliman, Abdel-Hady B. Kashyout \\ Advanced Technology and New Materials Research Institute, Mubarak City for Scientific Research and \\ Technology Applications, Alexandria, Egypt \\ E-mail: h.soliman@mucsat.sci.eg
}

Received March 25, 2011; revised May 20, 2011; accepted May 28, 2011

\begin{abstract}
Bismuth telluride thick films are suitable for thermoelectric (TE) devices covering large areas and operating at small-to-moderate temperature differences $(20-200 \mathrm{~K})$. High efficiency and high coefficient of performance (COP) are expected to be achieved by using thick films in some cooling applications. Bismuth telluride thick films fabrication have been achieved with Galvanostatic and Potentionstatic deposition. Stoichiometric bismuth telluride thick film was obtained by Galvanostatic deposition at current density of 3.1 $\mathrm{mA} \cdot \mathrm{cm}^{-2}$. Bismuth telluride films with average growth rate of $10 \mu \mathrm{m} \cdot \mathrm{h}^{-1}$ and different composition were obtained. Effects of current density and composition of electrolyte in Galvanostatic deposition were studied. The current density affected the film compactness, where films deposited at lower current density were more compact than those deposited at higher current density. The morphology of the films did not depend on the current density, but chemical composition was observed when different composition of electrolyte was used. Effects of distance between electrodes, composition of electrolyte solution, and stirring in Potentionstatic deposition were studied. The shorter the distance between electrodes, the higher the electric field, thus the higher current density was applied and the deposited film was less compact. The current density increased more rapidly with stirring during electrodeposition which leads to less compact film. Through this study, films electrodeposited from solution containing $0.013 \mathrm{M} \mathrm{Bi}\left(\mathrm{NO}_{3}\right)_{3} \cdot 5 \mathrm{H}_{2} \mathrm{O}, 0.01 \mathrm{M} \mathrm{TeO}_{2}$ and $1 \mathrm{M} \mathrm{HNO}_{3}$ at 3.1 $\mathrm{mA} \cdot \mathrm{cm}^{-2}$ for 6 hours without stirring and with inter-electrode distance of $4.5 \mathrm{~cm}$ were free-standing with average film thickness of $60 \mu \mathrm{m}$ and optimum film composition of $\mathrm{Bi}_{2} \mathrm{Te}_{3}$. The crystallite size of the later films was found to be around $4.3 \mathrm{~nm}$ using Scherrer's equation from XRD patterns. Also, negative Seebeck coefficient for the same samples was revealed with an average value of $-82 \mu \mathrm{V} \cdot \mathrm{K}^{-1}$.
\end{abstract}

Keywords: Bismuth Telluride, Thermoelectric, Electrodeposition, Nanostructure, Thick Film

\section{Introduction}

Thermoelectric (TE) materials can convert the difference in temperature into electric voltage and vice versa. The performance of TE materials is measured by TE dimensionless figure-of-merit, ZT [1]:

$$
Z T=\frac{S^{2} \sigma}{\kappa} T, \kappa=\kappa_{e}+\kappa_{L}
$$

where $S$ Seebeck coefficient in volts per Kelvin, $\sigma$ electrical conductivity in Siemens per meter, $\kappa$ thermal conductivity in Watts per meter Kelvin; includes electronic $\left(\kappa_{e}\right)$ and lattice thermal conductivity $\left(\kappa_{L}\right)$, T temperature in Kelvin.

The past two decades from 1990 have witnessed an increased interest for TE and significant research efforts. Attempts for improving TE material properties can be summarized into two different research approaches: one identifying new families of advanced bulk TE materials, and the other using low-dimensional material systems [2]. For the advanced bulk material approach, host-guest crystal structures with rattling atoms, e.g. skutterudites, clathrates and half-hausler materials, were introduced [3]. This is also called "phonon glass electron crystal" material. The skutterudites, such as $\mathrm{CeFe}_{3} \mathrm{CoSb}_{12}$, with $\mathrm{Ce}$ as 'rattler' atoms in atomic cages, are a family of com- 
pounds that has a potential for remarkable performance improvement since their thermal conductivity is relatively low. Regarding the low-dimensional material approach, the introduction of nano-structured (NS) constituents would introduce quantum-confinement effects to enhance the power factor, $S^{2} \sigma$. More importantly, NS materials with grain size in the nanometer regime have significant amount of grain boundaries. Grain boundaries are more selective for the diffraction of phonon as compared to that of electrons. This would result in a significant decrease in thermal conductivities and a relatively smaller decrease of electrical conductivity, which leads to an improvement of the $Z T$.

Nanostructured (NS) materials are known to exhibit different physical properties than in bulk structure. Their grain boundaries become predominant in determining the materials' properties. With the selective scattering phonons by the grain boundaries, the lattice thermal conductivity of a nanostructured TE material can be lowered, resulting in an enhancement of TE performance. Bismuth telluride is a TE material that can be used for cooling application devices due to its superior TE dimensionless figure of merit, ZT, near room temperature [2]. By varying the composition from its stoichiometric composition $\left(\mathrm{Bi}_{2} \mathrm{Te}_{3}\right)$, bismuth telluride can be tailored to be n-type $\left(\mathrm{Bi}_{2-\mathrm{x}} \mathrm{Te}_{3+\mathrm{x}}\right)$ or p-type semiconductors $\left(\mathrm{Bi}_{2+\mathrm{x}} \mathrm{Te}_{3-\mathrm{x}}\right)$. Bismuth telluride films and powder can be synthesized by various methods (evaporation, MOCVD, ball milling and electrodeposition) [4,5]. Electrodeposition technique is an attractive technique because it has many advantages including cost-effectiveness, rapid deposition rates, etc. Novel TE module technology based on thick films exhibits 1) more suitable for application in devices covering large areas and operating at small to moderate $\Delta \mathrm{T}, 2$ ) influence of electrical and thermal contact and spreading resistance is low, and 3) high efficiency and high coefficient of performance (COP) can be achieved with flux quantities being about one order of magnitude larger than conventional devices. NS bismuth telluride thick films with a thickness up to $350 \mu \mathrm{m}$ have been obtained, with a very high homogeneity and a high electrical conductivity [6]. Also, annealing and doping (n/p-type) effects on the thick films have been investigated [7].

In order to enhance the performance of nanostructured bismuth telluride, electrodeposition conditions must be further optimized. The aim of this work is to manipulate and to optimize the different parameters controlling the electrochemical deposition of bismuth telluride thick films to abstract the best deposition conditions to shed more light on the process as part of full comprehensive plan to enhance the figure-of-merit. These parameters include current density, deposition potential, $\mathrm{Bi}$ and $\mathrm{Te}$ concentrations, stirring and inter-electrodes separation distance were studied to optimize $\mathrm{Bi}_{2} \mathrm{Te}_{3}$ thick films.

\section{Experimental}

\subsection{Solutions and Samples Preparation}

The electrolyte solution was prepared by adding the weighted amounts of $\mathrm{Bi}\left(\mathrm{NO}_{3}\right)_{3} 5 \mathrm{H}_{2} \mathrm{O}$ and $\mathrm{TeO}_{2}$ powders in a beaker filled with deionized water with continuous stirring on hot plate and slowly adding the measured volume of $\mathrm{HNO}_{3}$ to the solution. The solution was kept boiling until it became clear. The beaker was taken off from the hot plate and the solution was left to cool down to room temperature. The electrolyte solution was transferred into the volumetric flask. The washing bottle with deionised water was used to wash the remaining solution from the beaker and the water was then transferred into the volumetric flask. This was repeated until the solution reached the $1000 \mathrm{ML}$ mark. It was transferred into the tightly closed bottle to avoid the evaporation during the storage. Nitrogen gas was bubbled into the electrolyte for 10 minutes to remove oxygen from the solution prior to the electrodeposition.

$99.99 \%$ aluminum plate of thickness $0.1 \mathrm{~mm}$ was used as the base of working electrode. The plate was cut into strips of $1 \mathrm{~cm}$ width, polished by diamond paste, and cut into pieces of about $3.5 \mathrm{~cm}$ length each. They were then washed by acetone with ultrasonicator, deionised water, and ethanol, and left to dry in air. They were sputtered with gold $\sim 100 \mathrm{~nm}$ thick on one side and then coated the non-sputtered side for insulation and coated sputtered side leaving area of $2 \mathrm{~cm}^{2}$ sputtered gold for deposition of bismuth telluride onto the substrate and top part of the substrate for connecting with Potentiostat/Galvanostat. The substrate was washed with deionised water before use. The platinum counter electrode was flattened and then washed with concentrated $\mathrm{HNO}_{3}$ and deionised water. The growth time was around 6 hours.

\subsection{Deposition Conditions}

\subsubsection{Galvanostatic Deposition}

Galvanostatic deposition of bismuth telluride films was done in two-electrode cell at room temperature. The effects of current density and composition of the electrolyte solution on morphology, compactness, and stoichiometry of films were studied as the conditions stated in Table 1.

\subsubsection{Potentionstatic Deposition}

A voltammogram was obtained by a three-electrode cell connected to an EG\&G Princeton Applied Research 263A Potentiostat/Galvanostat at room temperature. The 
Table 1. Conditions for Galvanostatic deposition of bismuth telluride films.

\begin{tabular}{cccc}
\hline \multirow{2}{*}{ Sample } & $\begin{array}{c}\text { Current Density } \\
\left(\mathrm{mA} \cdot \mathrm{cm}^{-2}\right)\end{array}$ & \multicolumn{2}{c}{ Composition of Electrolyte } \\
\cline { 3 - 4 } & 3.1 & $\mathrm{Bi}(\mathrm{M}): \mathrm{Te}(\mathrm{M})$ & $\mathrm{Bi}: \mathrm{Te}$ \\
\hline $\mathrm{G}-1$ & 3.5 & $0.013: 0.010$ & $4: 3$ \\
$\mathrm{G}-2$ & 3.5 & $0.0033: 0.020$ & $4: 3$ \\
$\mathrm{G}-3$ & & & $1: 6$ \\
\hline
\end{tabular}

electrolyte solution was deaerated by bubbling nitrogen through the solution for 10 minutes prior the experiment. All potentials were measured and were expressed relative to the aqueous $\mathrm{AgCl}$ saturated calomel electrode (SCE), reference electrode (RE). The gold sputtered aluminum sheet with area of $2 \mathrm{~cm}^{2}$ was used as working electrode (WE). The counter electrode (CE) was a platinum plate with area $\left(\sim 6 \mathrm{~cm}^{2}\right)$ larger than the working electrode. $0.013 \mathrm{M}$ of bismuth nitrate pentahydrate $\left[\mathrm{Bi}\left(\mathrm{NO}_{3}\right)_{3} \cdot 5\right.$ $\left.\mathrm{H}_{2} \mathrm{O}\right], 0.01 \mathrm{M}$ of tellurium dioxide $\left(\mathrm{TeO}_{2}\right), 1 \mathrm{M}$ of nitric acid $\left(\mathrm{HNO}_{3}\right)$, and deionised water; 1 liter of electrolyte solution was prepared. This concentration was determined by the previous work of Miyazaki, et al. [8]. This is referred as solution a in this work. Another electrolyte solution was prepared in order to study the change in composition if the electrolyte solution was tellurium rich solution with $0.0033 \mathrm{M} \mathrm{Bi}\left(\mathrm{NO}_{3}\right)_{3} \cdot 5 \mathrm{H}_{2} \mathrm{O}, 0.02 \mathrm{M} \mathrm{TeO}_{2}$, and $1 \mathrm{M} \mathrm{HNO}_{3}$, and deionised water; 1 liter of electrolyte solution was prepared. This is referred as solution $\mathbf{b}$ in this work. Potentionstatic deposition of bismuth telluride films was done in three-electrode cell with reference electrode facing the working electrode and about $0.5 \mathrm{~cm}$ apart from each other at room temperature. The voltammograms for both solutions were obtained from $0.4 \mathrm{~V}$ to $-0.6 \mathrm{~V}$ at the scan rate $0.5 \mathrm{mV} \cdot \mathrm{s}^{-1}$. The effects of distance between electrodes, stirring, and composition of the electrolyte on morphology, compactness, and stoichiometry of films were studied and the preparation conditions are summarized in Table 2.

\subsection{Film Characterization}

After electrodeposition, samples were removed from the electrolyte, rinsed with water and ethanol, and dried in air. XRD patterns of the films were obtained using a Philips PW 1012/20 and 3020 diffractometer with $\mathrm{Cu}$ $\mathrm{K} \alpha_{1}$ radiation. The average crystallite size, $D$, could be calculated from the peak broadening of the diffraction pattern, using Scherrer's equation [9], $D=0.9 \lambda /(\beta \cos \theta)$, where $\beta$ is the pure diffraction line width, full width at half maximum, and $\lambda$ is X-ray wavelength $\left(\mathrm{Cu} \mathrm{K} \alpha_{1}, \lambda=\right.$ $1.54056 \AA$ \&). Electrodeposited bismuth telluride thick films were imaged with scanning electron microscopy (SEM, JEOL JSM-888) equipped with energy dispersive $\mathrm{X}$-ray spectrometer (EDS) which was used for composition analysis. The thickness of the films was determined by measuring the edge of the film from the side under SEM.

\subsection{Seebeck Coefficient Measurement}

Seebeck coefficient of film electrodeposited from solution containing $0.013 \mathrm{M} \mathrm{Bi}\left(\mathrm{NO}_{3}\right)_{3} \cdot 5 \mathrm{H}_{2} \mathrm{O}, 0.01 \mathrm{M} \mathrm{TeO}_{2}$ and $1 \mathrm{M} \mathrm{HNO}_{3}$ at $3.1 \mathrm{~mA} \cdot \mathrm{cm}^{-2}$ for 6 hours without stirring and with inter-electrode distance of $4.5 \mathrm{~cm}$ has been measured. The Seebeck Microprobe (SMP) is a device for measuring the Seebeck coefficient on the sample surface with a spatial resolution down to $10-50 \mu \mathrm{m}$ (depending on the thermal conductivity of the material). A heated probe tip is positioned onto the sample surface. The sample is fixed in good electrical and thermal contact to a heat sink and is connected to another thermocouple measuring the sink temperature. The heat flow from the probe tip to the sample causes a local temperature gradient in the vicinity of the tip. Mounting the probe to a three-dimensional micropositioning system allows for the determination of the thermopower at each microposition of the sample surface. The result is a twodimensional image of the Seebeck coefficient $[10,11]$. Special sample holders have been developed to mechanically fix thick films as well to ensure simultaneously good electrical and thermal contact as a precondition for a high quality measurement. The SMP apparatus has been improved by adding an electronic contact detection system so that the probe tip will stop its movement immediately after touching the sample to avoid

Table 2. Conditions for Potentionstatic deposition of bismuth telluride films.

\begin{tabular}{|c|c|c|c|c|c|}
\hline \multirow{2}{*}{ Sample } & \multirow{2}{*}{ Potential vs. SCE (mV) } & \multicolumn{2}{|c|}{ Composition of Electrolyte } & \multirow{2}{*}{ Stirring } & \multirow{2}{*}{ Distance between Electrodes $(\mathrm{cm})$} \\
\hline & & $\mathrm{Bi}(\mathrm{M}): \mathrm{Te}(\mathrm{M})$ & Bi:Te & & \\
\hline $\mathrm{P}-1$ & -120 & 0.013:0.010 & $4: 3$ & No & 4.5 \\
\hline P-2 & -120 & 0.013:0.010 & $4: 3$ & No & 3 \\
\hline $\mathrm{P}-3$ & -120 & 0.013:0.010 & $4: 3$ & Yes & 4.5 \\
\hline P-4 & -120 & 0.0033:0.020 & $1: 6$ & No & 4.5 \\
\hline
\end{tabular}


destruction of the films.

Seebeck coefficient measurement is a tool to detect the distribution of different electrically active components in the materials. It is capable of detecting functional inhomogeneities, different phases, even small differences in doping concentration, which cannot be detected by other surface analysis methods such as SEM, EDS, etc. Measuring the Seebeck coefficient of films could be difficult, because the local temperature gradient caused by the probe tip can also heat the materials of the supporting substrate, yielding an integration of the Seebeck coefficient of the sample and the substrate. If the substrate has a very low thermal coupling, this effect will be negligible. The TE thick films were deposited onto Au-coated Al substrate with very good thermal coupling, which could lead to erroneous measurements. Taking into account the thickness of the samples of more than $100 \mu \mathrm{m}$, this effect will disappear or at least attenuate, because the local temperature gradient will not exceed a certain depth of an estimated $50 \mu \mathrm{m}$ in bismuth telluride. Recent results show that indeed it is now possible to measure the influence of a substrate and estimate the depth of temperature gradient [12].

\section{Results and Discussion}

\subsection{Voltammetry}

The electrochemical deposition of bismuth telluride has been well investigated [13]. Bismuth nitrate pentahydrate and tellurium dioxide were dissolved in nitric acid to make the oxide cations, $\mathrm{BiO}^{+}$and $\mathrm{HTeO}_{2}^{+} . \mathrm{Bi}_{2} \mathrm{Te}_{3}$ is insoluble in dilute $\mathrm{HNO}_{3}$, so reduction of $\mathrm{HTeO}_{2}{ }^{+}$to $\mathrm{Te}^{2-}$ at the cathode will result in the precipitation of $\mathrm{Bi}_{2} \mathrm{Te}_{3}$ on the cathode surface. The overall reaction for the process is:

$$
13 \mathrm{H}^{+}+18 \mathrm{e}^{-}+2 \mathrm{BiO}^{+}+3 \mathrm{HTeO}_{2}^{+} \rightarrow \mathrm{Bi}_{2} \mathrm{Te}_{3(\mathrm{~s})}+8 \mathrm{H}_{2} \mathrm{O}
$$

Martin-Gonzalez, et al. [14] found that when there is only $\mathrm{HTeO}_{2}^{+}$in nitric acid solution, reduction of cations occurred at around $-240 \mathrm{mV}$ and $-600 \mathrm{mV}$. Fleurial, et al. [15] found that $\mathrm{BiO}^{+}$was reduced to $\mathrm{Bi}^{0}$ around $-100 \mathrm{mV}$. It is noteworthy that solution a was bismuth-rich while solution $\mathbf{b}$ was tellurium-rich. Due to more concentration of $\mathrm{BiO}^{+}$in solution a than $\mathrm{HTeO}_{2}{ }^{+}$, the potential range $(0$ to $-300 \mathrm{mV}, \mathrm{i}=-3$ to -3.9 $\mathrm{mA} \cdot \mathrm{cm}^{-2}$ ) for electrodeposition was smaller than the potential range for solution $\mathbf{b}(0$ to $-550 \mathrm{mV}, \mathrm{i}=-2.6$ to $-3.8 \mathrm{~mA} \cdot \mathrm{cm}^{-2}$ ).

From the previous investigation by Takahashi et al. [13], the limiting current was affected by the concentration of $\mathrm{Bi}\left(\mathrm{NO}_{3}\right)_{3} 5 \mathrm{H}_{2} \mathrm{O}$ and $\mathrm{TeO}_{2}$. The limiting current is a diffusion current of a process limited by ion diffusions.
The limiting current increases with the increase of ions concentration. However, in solution $\mathbf{b}$, the concentration of $\mathrm{BiO}^{+}$cations was $0.01 \mathrm{M}$ less and the concentration of $\mathrm{HTeO}_{2}^{+}$cations was $0.01 \mathrm{M}$ more than that of solution a, the overall limiting current density less than that of solution a at more negative potential than $-200 \mathrm{mV}$. The cathodic current increased more rapidly at potentials more negative than $-300 \mathrm{mV}$ for solution a and -550 $\mathrm{mV}$ for solution $\mathbf{b}$.

\subsubsection{Galvanostatic Deposition}

In the Galvanostatic deposition experiments, different current densities and different compositions of electrolyte were tested and studied. Their effects on the morphology, compactness, and stoichiometry of the deposited films were investigated. The potential was applied to keep the current in the electrochemical cell constant during the deposition experiments.

\subsubsection{Effect of Current Density}

Current densities of 3.1 and $3.5 \mathrm{~mA} \cdot \mathrm{cm}^{-2}$ were tested for solution a. From low resolution SEM images as shown in Figure 1, the film deposited at lower current density was more compact than the film deposited at higher current density. At higher current density, the diffusion rate of the ions was faster and caused the deposition rate to be faster. Thus, at higher current density, the deposited material was 3D dendritic structure and it did not show a compact performance.

This can be clearly seen in high resolution SEM images in Figure 2 where the fine structures on the film obtained at the higher current density appeared 'flaky' and showed dendritic nanostructure in comparison to the more compact fine grains obtained at current density of $3.1 \mathrm{~mA} \cdot \mathrm{cm}^{-2}$. However, the structures of both films were very similar in the sense of the shape, dendrite, thus the morphology does not affect by current density.

The stoichiometry was $\mathrm{Bi}_{2} \mathrm{Te}_{3}$ for the film deposited at current density $3.1 \mathrm{~mA} \cdot \mathrm{cm}^{-2}$. The ratio of Bi to Te for the film deposited at current density $3.5 \mathrm{~mA} \cdot \mathrm{cm}^{-2}$ is $2.6: 2.4$. Electrodeposited films of the same composition of elec-

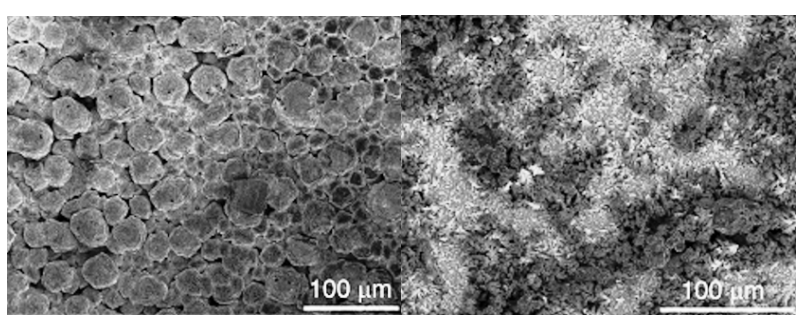

(a)

(b)

Figure 1. Low resolution SEM image of $\mathrm{Bi}_{2} \mathrm{Te}_{3}$ thick films deposited Galvanostatically, (a) Sample G-1 and (b) Sample G-2 in Table 1. 


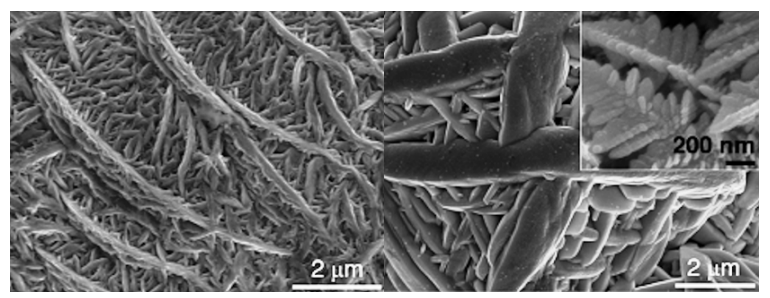

(a)

(b)

Figure 2. High resolution $\mathrm{SEM}$ images of $\mathrm{Bi}_{2} \mathrm{Te}_{3}$ thick films deposited Galvanostatically; (a) Sample G-1 and (b) Sample G-2 in Table 1.

trolyte solution did not give the same composition of the films when it was deposited at different current density. Te contents decreased as the current density increased which was also observed by Michel et al. [16]. In this experiment, Te atomic percentage in film was less than $60 \%$ when deposition above $3.1 \mathrm{~mA} \cdot \mathrm{cm}^{-2}$ for solution $\mathbf{a}$.

\subsubsection{Effect of Composition of Electrolyte Solution} Composition of electrolyte solutions of $0.013 \mathrm{M} \mathrm{BiO}^{+}$and $0.01 \mathrm{M} \mathrm{HTeO}_{2}^{+}$for solution $\mathbf{a}$ and $0.0033 \mathrm{M} \mathrm{BiO}^{+}$and $0.02 \mathrm{M} \mathrm{HTeO}_{2}^{+}$for solution b were tested at 3.5 $\mathrm{mA} \cdot \mathrm{cm}^{-2}$. From high resolution SEM images shown in Figure 3, the film deposited from solution a was less compact with smaller structure than the film deposited from solution $\mathbf{b}$. The film deposited from solution $\mathbf{b}$ had spherical structure. It has been found that the morphology of the films significantly depends on the chemical composition of the alloys rather than on the synthesis conditions.

The stoichiometry of bismuth telluride films was $\mathrm{Bi}_{2.6} \mathrm{Te}_{2.4}$ for solution a (sample G-2) and $\mathrm{Bi}_{0.7} \mathrm{Te}_{4.3}$ for solution b (sample G-3). The high Bi and low Te contents film from solution a was formed by agglomerated polycrystalline forming incoherent deposit. The low Bi and high Te contents film from solution $\mathbf{b}$ was formed by small crystals forming a coherent or compact deposit.

\subsubsection{Potentiostatic Deposition}

In the Potentionstatic deposition experiments, different distances between electrodes, different stirrings, and different composition of electrolytes were tested and studied. Their effects on the morphology, compactness, and stoichiometry of the deposited films were investigated. The current was applied to keep the potential in the electrochemical cell constant during the deposition experiments. The potential of $-120 \mathrm{mV}$ was used for deposition of the films. The morphology was determined by SEM and the stoichiometry of the films was determined using EDS.

\subsubsection{Effect of Distance between Electrodes}

Distances between electrodes of 3 and $4.5 \mathrm{~cm}$ were tested for solution a. From low resolution SEM images as shown in Figure 4, the film deposited with longer distance (sample P-1), was more compact than the film deposited with shorter distance (sample P-2). The potential applied for both case was the same, however the electric field was depended on the distance between electrodes. The shorter the distance between electrodes, the higher the electric field, thus the higher current density was applied due to Ohm's Law. As mentioned before in the Galvanostatic deposition that at higher current density, the deposited film was less compact due to the diffusion rate of ions. Higher resolution SEM images showed that the morphology of both samples were similar, thus the morphology does not depend on the distance between electrodes.

The stoichiometry was $\mathrm{Bi}_{2.8} \mathrm{Te}_{2.2}$ for sample $\mathrm{P}-1$ and $\mathrm{Bi}_{2.7} \mathrm{Te}_{2.3}$ for sample P-2. Electrodeposited films from the same electrolyte solution did not give the same composition of Bi:Te in the films when it was deposited at different distance between electrodes. The shorter the distance, the higher current density, thus Te contents should decrease. However, the Te contents increased when the distance between electrodes was shorter. The lower contents of Te could refer to the change in the flow mechanism from laminar into turbulent caused by the vigorous oxygen evolution at the counter electrode surface due to the short inter-electrode distance or, consecutively, the higher current density [17].

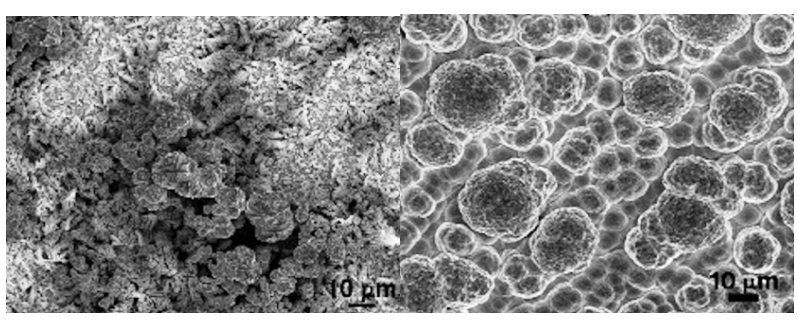

(a)

(b)

Figure 3. High resolution $\mathrm{SEM}$ images of $\mathrm{Bi}_{2} \mathrm{Te}_{3}$ thick films deposited Galvanostatically at $3.5 \mathrm{~mA} \mathrm{~cm}$ from solution a; (a) sample G-2 and from solution b; (b) sample G-3 in Table 1.

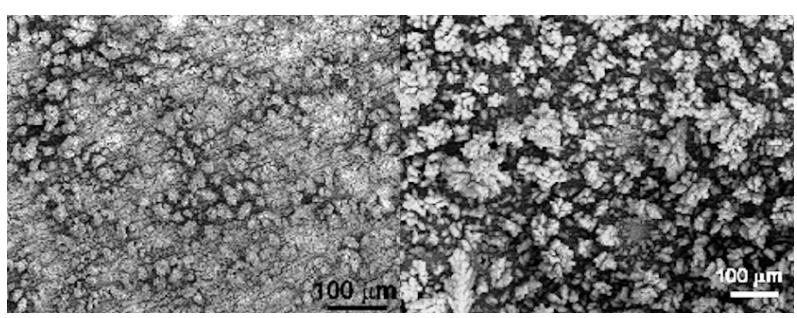

(a)

(b)

Figure 4. Low resolution $\mathrm{SEM}$ images of $\mathrm{Bi}_{2} \mathrm{Te}_{3}$ thick films deposited Potentiostatically at $-120 \mathrm{mV}$ with $4.5 \mathrm{~cm}$; (a) Sample P-1), and with $3 \mathrm{~cm}$ (b) sample P-2 in Table 2. 


\subsubsection{Effect of Stirring}

Electrodeposition with and without stirring was tested for solution a. From high resolution SEM images as shown in Figure 5, the film deposited without stirring (sample P-1), was more compact than the film deposited with stirring (sample P-3). The images also showed that the morphology of both samples was similar, dendritic, thus the morphology does not depend on stirring.

From voltammogram shown in Figure 6, the current density increased more rapidly with stirring compared to the electrodeposition current density without stirring. Stirring increased the rate of diffusion of ions, thus current density increases, resulting in less compact film. The stoichiometry was $\mathrm{Bi}_{2.8} \mathrm{Te}_{2.2}$ for sample $\mathrm{P}-1$ and $\mathrm{Bi}_{2.7} \mathrm{Te}_{2.3}$ for sample P-3. Electrodeposited films of the same composition of electrolyte solution did not give the same composition of Bi:Te in the films when it was deposited at different stirring rates. The more stirring, the higher current density it was, thus Te contents should decrease. However, the Te contents increased with stirring and could be explained as the same previously mentioned reason on studying the effect of distance between electrodes [17].

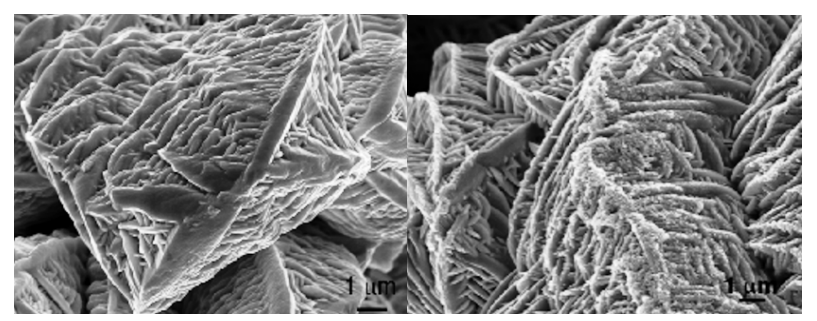

(a)

(b)

Figure 5. High resolution $\mathrm{SEM}$ images of $\mathrm{Bi}_{2} \mathrm{Te}_{3}$ thick films deposited Potentiostatically at $-120 \mathrm{mV}$ with no stirring; (a) Sample P-1 and Sample P-3 Table 2.

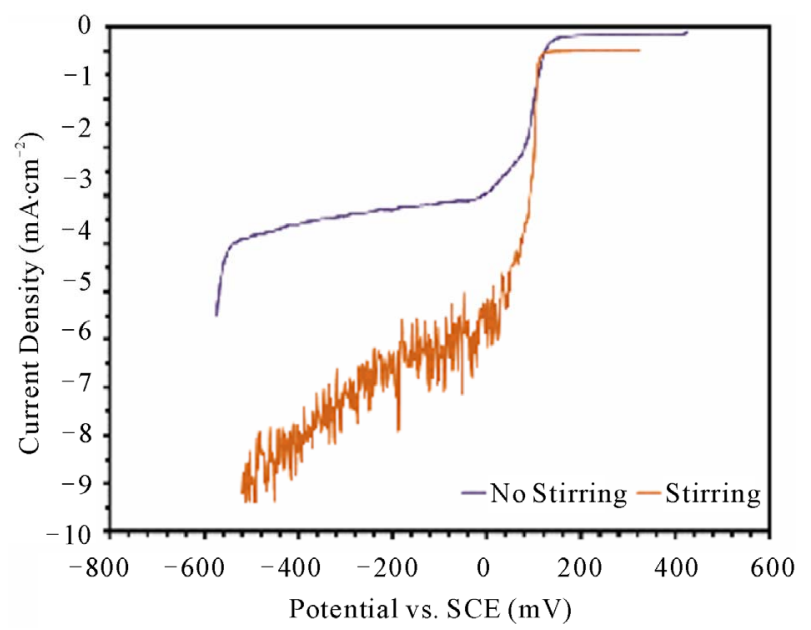

Figure 6. Voltammogram of solution a with a scan rate of $0.5 \mathrm{mV} \cdot \mathrm{s}^{-1}$, with and without stirring.

\subsubsection{Effect of Composition of Electrolyte Solution}

Composition of electrolyte solutions of $0.013 \mathrm{M} \mathrm{BiO}^{+}$and $0.01 \mathrm{M} \mathrm{HTeO}_{2}^{+}$for solution a and $0.0033 \mathrm{M} \mathrm{BiO}^{+}$and $0.02 \mathrm{M} \mathrm{HTeO}_{2}{ }^{+}$for solution $\mathbf{b}$ were tested at $-120 \mathrm{mV}$. From high resolution SEM images shown in Figure 7, the film deposited from solution a was less compact with smaller structure than the film deposited from solution $\mathbf{b}$. The film deposited in solution $\mathbf{b}$ had spherical dendrite structure. As mentioned before, the morphology of the films depends on the chemical composition of the alloys.

The stoichiometry was $\mathrm{Bi}_{2.8} \mathrm{Te}_{2.2}$ for sample $\mathrm{P}-1$ and $\mathrm{Bi}_{0.4} \mathrm{Te}_{4.6}$ for sample P-4 The high $\mathrm{Bi}$ and low Te contents film from solution a was formed by agglomerated polycrystalline forming incoherent deposit, thus formed smaller structure. The low $\mathrm{Bi}$ and high Te contents film from solution $\mathbf{b}$ was formed by small crystals forming a coherent deposit, however not as compact as a film.

\subsection{Microstructure and Seebeck Coefficient}

\subsubsection{Microstructure}

Through the previous study, films electrodeposited from solution a at $3.1 \mathrm{~mA} \cdot \mathrm{cm}^{-2}$ for 6 hours without stirring and with inter-electrode distance of $4.5 \mathrm{~cm}$ were freestanding samples and the best accomplishment in this study. Figure 8 shows the main features of the morphology at these conditions along with the average thickness of $\sim 60 \mu \mathrm{m}$ (inset), the growth rate was 10 $\mu \mathrm{m} \cdot \mathrm{h}^{-1}$, while the EDS analysis, Figure 9 and Table 3, give the film composition as $\mathrm{Bi}_{2.0255} \mathrm{Te}_{2.9745}$ or $\sim \mathrm{Bi}_{2} \mathrm{Te}_{3}$.

Figure 10 shows the typical XRD pattern of film electrochemically deposited from solution a at $3.1 \mathrm{~mA} \cdot \mathrm{cm}^{-2}$ for 6 hours without stirring and with inter-electrode distance of $4.5 \mathrm{~cm}$. It is observed that the film is polycrystalline bismuth telluride with the (110) as the prominent plane parallel to the substrate. According to the standard ICDD PDF card (08-0021), all of the detected peaks are indexed as those from the rhombohedra $\mathrm{Bi}_{2} \mathrm{Te}_{3}$ crystal and no second phase has been detected. The average grain size of the films was calculated to be $4.3 \mathrm{~nm}$ based on Scherrer's equation.

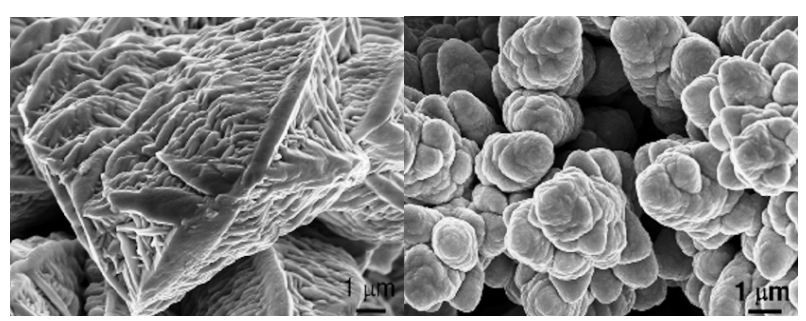

(a)

(b)

Figure 7. High resolution $\mathrm{SEM}$ image of $\mathrm{Bi}_{2} \mathrm{Te}_{3}$ thick films deposited Potentiostatically at $-120 \mathrm{mV}$ from solution a (a) Sample P-1) and solution b, (b) Sample P-3. 


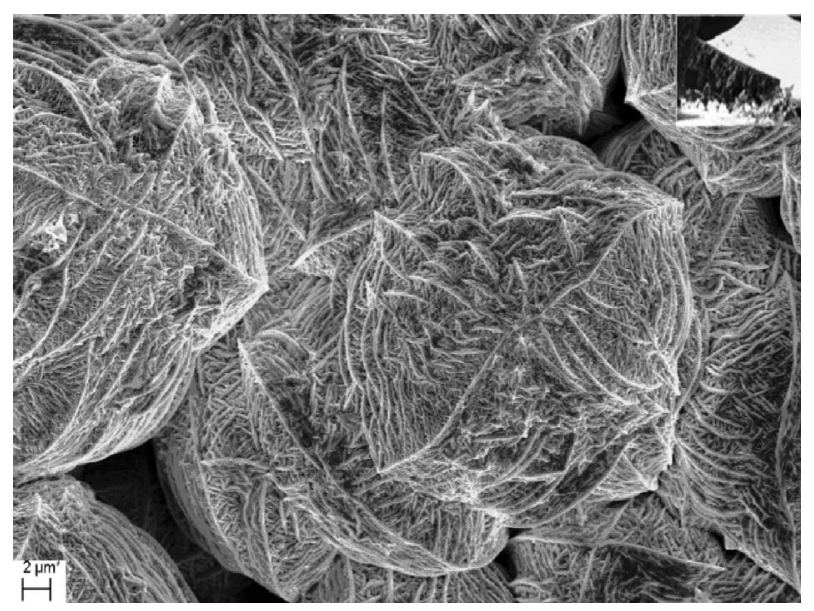

Figure 8. SEM micrograph of $\mathrm{Bi}_{2} \mathrm{Te}_{3}$ film deposited Galvanostatically at $3.1 \mathrm{~mA} \cdot \mathrm{cm}^{-2}$ for 6 hours without stirring and with inter-electrode distance of $4.5 \mathrm{~cm}$. Average thickness of $\sim 60 \mu \mathrm{m}$ (inset).

\subsubsection{Seebeck Coefficient}

Figure 11 shows the spatial distribution of the Seebeck coefficient of the film electrochemically deposited from solution a at $3.1 \mathrm{~mA} \cdot \mathrm{cm}^{-2}$ for 6 hours without stirring and with inter-electrode distance of $4.5 \mathrm{~cm}$. The resolution was $50 \mu \mathrm{m}$ in $\mathrm{X}$ and $\mathrm{Y}$ directions. The absolute value of Seebeck coefficient is around $-82 \mu \mathrm{V} \cdot \mathrm{K}^{-1}$, which is negative and thus possessing an $n$-type conductivity.

The sign of Seebeck coefficient can be determined by the two-carrier electrical conduction. Taking into account the mixed conductivity model, the total Seebeck coefficient can be expressed as [18]:

$$
S=\left(S_{p} \sigma_{p}+S_{n} \sigma_{n}\right) /\left(\sigma_{p}+\sigma_{n}\right)
$$

where $S_{p}, S_{n}$ and $\sigma_{p}, \sigma_{n}$ are the Seebeck coefficients and electrical conductivities for the $\mathrm{p}$ - and $n$-type carriers, respectively. In addition:

$$
\begin{aligned}
& S= \pm \frac{k_{B}}{e}\left[(r+2)+\ln \frac{\left(2\left(2 \pi m^{*} k_{B} T\right)^{3 / 2}\right.}{n h^{3}}\right] \\
& \sigma=\text { ne } \mu
\end{aligned}
$$

where $k_{B}$ is the Boltzmann's constant, $e$ is the electron charge, $r$ is the scattering factor, $m^{*}$ is effective mass, $h$ is the Planck constant, $n$ is the carrier concentration, and $\mu$ is carrier mobility. Since the signs of $S_{p}$ and $S_{n}$ are op-

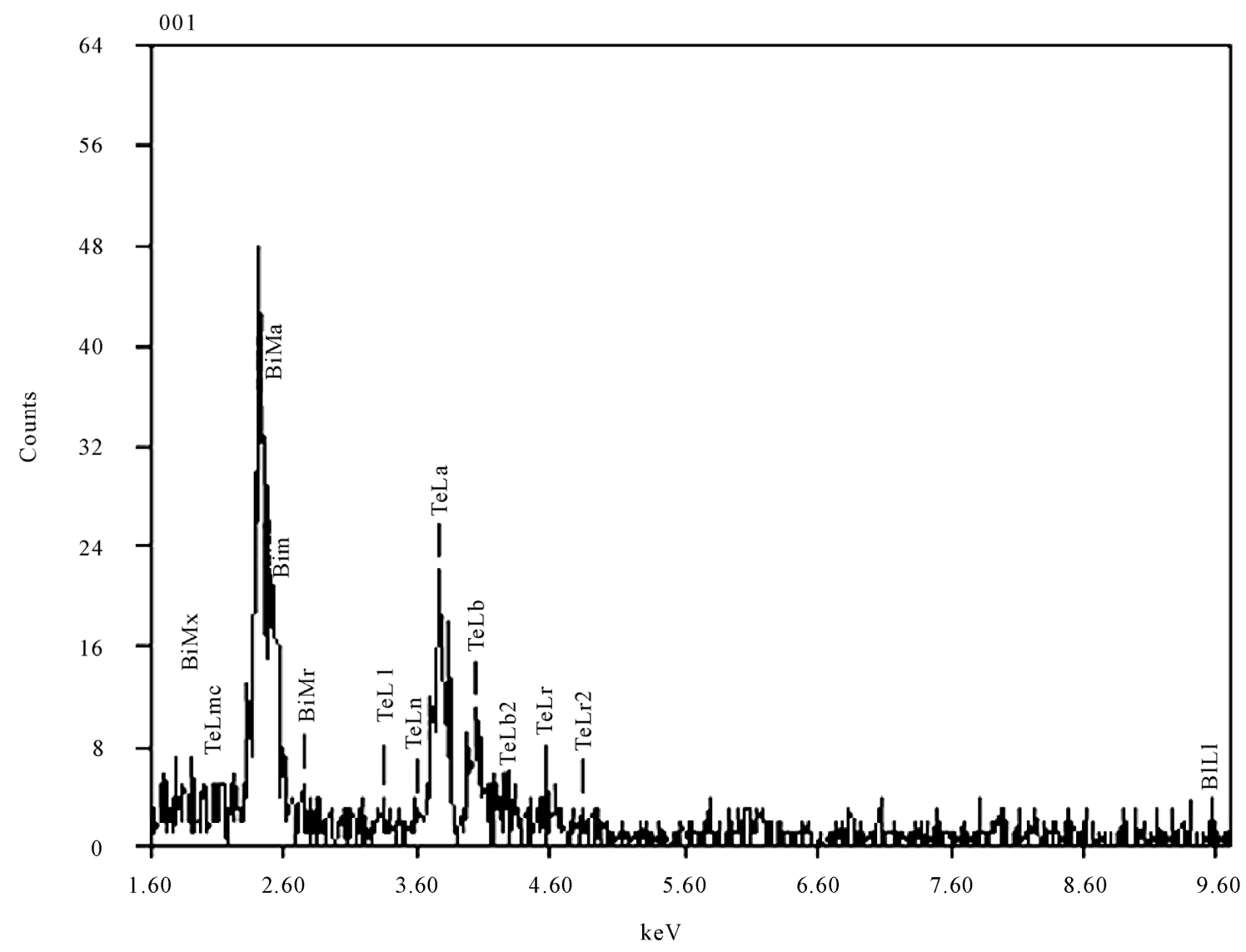

Figure 9. EDS elemental analysis of $\mathrm{Bi}_{2} \mathrm{Te}_{3}$ film deposited Galvanostatically at $3.1 \mathrm{~mA} \cdot \mathrm{cm}^{-2}$ for 6 hours without stirring and with inter-electrode distance of $4.5 \mathrm{~cm}$. 
Table 3. EDS elemental Bi:Te weight $\%$ and atomic \% of bismuth telluride film electrodeposited at $3.1 \mathrm{~mA} \cdot \mathrm{cm}^{-2}$ for 6 hours without stirring and with inter-electrode distance of $4.5 \mathrm{~cm}$.

\begin{tabular}{ccc}
\hline Element & Weight\% & Atomic\% \\
\hline $\mathrm{Te}$ & 47.27 & 59.49 \\
$\mathrm{Bi}$ & 52.73 & 40.51 \\
Total & 100.00 & 100.00 \\
\hline
\end{tabular}

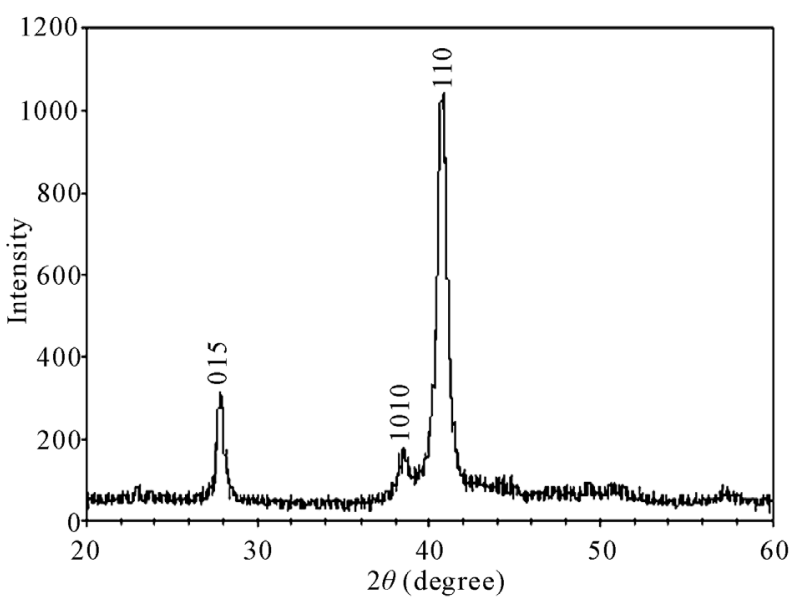

Figure 10. XRD patterns of film electrochemically deposited from solution a at $3.1 \mathrm{~mA} \cdot \mathrm{cm}^{-2}$ for 6 hours without stirring and with inter-electrode distance of $4.5 \mathrm{~cm}$.

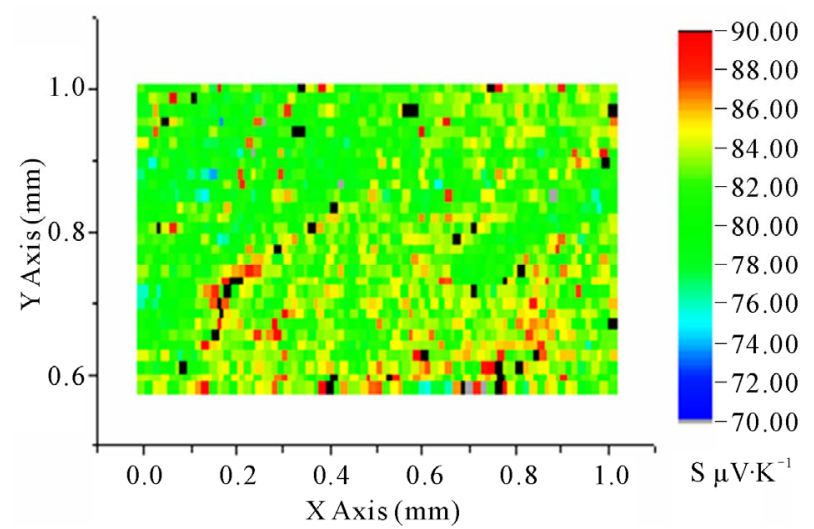

Figure 11. Spatial distribution of the Seebeck coefficient of film electrochemically deposited from solution a at 3.1 $\mathrm{mA} \cdot \mathrm{cm}^{-2}$ for 6 hours without stirring and with inter-electrode distance of $4.5 \mathrm{~cm}$.

posite, tuning the concentration of holes and electrons could change the sign of total Seebeck coefficient.

Table 3 provides the elemental analysis of the film, showing that the film is Bi-rich (40.5 at\%). Results from other researchers [19] also demonstrate the unclear relationship between type of conductivity or carrier concentration and stoichiometry of electrodeposited bismuth telluride films. The reason for n-type characteristics of Bi-rich electrodeposited bismuth telluride is not clear, but it is obvious that microstructures or structural imperfections at different conditions might affect the carrier concentration of electrodeposited bismuth telluride.

\section{Conclusions}

Bismuth telluride thick films fabrication have been achieved with Galvanostatic and Potentionstatic deposition. Stoichiometric bismuth telluride thick film was obtained by Galvanostatic deposition at $3.1 \mathrm{~mA} \cdot \mathrm{cm}^{-2}$. Bismuth telluride films of average growth rate of $10 \mu \mathrm{m} \cdot \mathrm{h}^{-1}$ with different composition were obtained. The effects of current density and composition of electrolyte solution in Galvanostatic deposition were studied. The current density affected the film compactness. The film deposited at lower current density was more compact than the film deposited at higher current density. The morphology of the films did not depend on the current density, but on chemical composition which was observed when the different composition of electrolyte solution was used. Effects of distance between electrodes, composition of electrolyte solution, and stirring in Potentionstatic deposition mode were studied. The shorter the distance between electrodes, the higher the electric field, thus the higher current density was applied and the deposited film was less compact. The current density increased more rapidly with stirring during electrodeposition resulting in less compact deposition. The morphology of the films did not depend neither on the distance between electrodes nor stirring rate, but chemical composition which was observed when the different composition of electrolyte solution was used during Potentionstatic deposition. From the study, electrodeposited films at higher current density, Te contents should decrease. Since stirring and shorter distance between electrodes increased the electrodeposition current density, it was expected to obtain film with low Te contents. However, the Te contents increased by stirring or longer distance between electrodes during Potentionstatic deposition. Films electrodeposited from solution a at $3.1 \mathrm{~mA} \cdot \mathrm{cm}^{-2}$ for 6 hours without stirring and with inter-electrode distance of 4.5 $\mathrm{cm}$ were free-standing samples with average Seebeck coefficient of $-82 \mu \mathrm{V} \cdot \mathrm{K}^{-1}$.

\section{Acknowledgements}

The authors gratefully acknowledge the Egyptian Science and Technology Development Fund (STDF) for funding this work among the STDF project No. 277 "Nanostructured Thick Films as Unconventional Alternatives to Power Generators and Coolers". 


\section{References}

[1] Y. Q. Cao, T. J. Zhu and X. B. Zhao, "Thermoelectric $\mathrm{Bi}_{2} \mathrm{Te}_{3}$ Nanotubes Synthesized by Low-Temperature Aqueous Chemical Method," Journal of Alloys and Compounds, Vol. 449, No. 1-2, January 2008, pp. 109112. doi:10.1016/j.jallcom.2006.01.116

[2] M. S. Dresselhaus, G. Chen, M. Y. Tang, R. Yang, H. Lee, D. Wang, Z. Ren, J. P. Fleurial and P. Gogna, "New Directions for Low-Dimensional Thermoelectric Materials," Advanced Materials, Vol. 19, No. 8, April 2007, pp. 1043-1053. doi:10.1002/adma.200600527

[3] T. Cailat, A. Borshevsky and J. P. Fleurial, "Use of Mechanical Alloying to Prepare and Investigate New Potential Thermoelectric Materials," Proc. XI Int. Conf. TEs., (Ed, K. R. Rao) Arlington, 1993, p. 9.

[4] C. H. Kuo, C. H. Hwanga, M. S. Jeng, W. S. Su, Y. W. Chou and J. R. Ku, "Thermoelectric Transport Properties of Bismuth Telluride Bulk Materials Fabricated by Ball Milling and Spark Plasma Sintering," Journal of Alloys and Compounds, Vol. 496, No. 1-2, April 2010, pp. 687-690. doi:10.1016/j.jallcom.2010.02.171

[5] J. Zhou, S. Li, H. M. A. Soliman, M. S. Toprak, M. Muhammed, D. Platzek and E. Muller, "Seebeck Coefficient of Nanostructured Phosphorus-Alloyed Bismuth Telluride Thick," Journal of Alloys and Compounds, Vol. 471, No. 1-2, March 2009, pp. 278-281. doi:10.1016/j.jallcom.2008.03.088

[6] S. Li, M. S. Toprak, H. M. A. Soliman and J. Zhou, "Fabrication of Nanostructured Thermoelectric Bismuth Telluride Thick Films by Electrochemical Deposition," Chemistry of Materials, Vol. 18, No. 16, July 2006, pp. 3627-3633. doi: $10.1021 / \mathrm{cm} 060171 \mathrm{o}$

[7] S. Li, H. M. A. Soliman, J. Zhou and M. S. Toprak, "Effects of Annealing and Doping on Nanostructured Bismuth Telluride Thick Films," Chemistry of Materials, Vol. 20, No. 13, July 2008, pp. 4403-4410. doi: $10.1021 / \mathrm{cm} 800696 \mathrm{~h}$

[8] Y. Miyazaki and T. Kajitani, "Preparation of $\mathrm{Bi}_{2} \mathrm{Te}_{3}$ Films by Electrodeposition," Journal of Crystal Growth, Vol. 229, No. 1-4, July 2001, pp. 542-546. doi:10.1016/S0022-0248(01)01225-8

[9] H. P. Klug and L. E. Alexander, "X-Ray Diffraction Procedures,” John Wiley \& Sons Inc., New York, 1954.

[10] P. Reinshaus, H. Süßmann, M. Bohm, A. Schuck and T. Dietrich, "Use of Mechanical Alloying to Prepare and Investigate New Potential Thermoelectric Materials," Proceedings of the 2nd European Symposium on Thermoelectrics: Materials, Processing Techniques, and Applications, Krakow, 15-17 September 2004, European
Thermoelectric Society, p. 90.

[11] D. Platzek, A. Zuber, C. Stiewe, G. Bähr, P. Reinshaus and E. Müller, "Anisotropy of the Seebeck Coefficient Detected by the Seebeck Scanning Microprobe," Proceedings of the 22nd International Conference on Thermoelectrics, LaGrande-Motte, 17-21 August 2003, IEEE, New York, 2004, p. 528.

[12] D. Platzek, G. Karpinski, C. Stiewe, P. Ziolkowski, M. Stordeur, B. Engers and E. Müller, "Spatial Resolution of the Seebeck Coefficient Measured on Thermoelectric Thin Films," 3rd European Conference on Thermoelectrics, Nancy, 1-2 September 2005, European Thermoelectric Society.

[13] M. Takahashi, Y. Oda, T. Ogino, S. Furuta, "Electrodeposition of Bi-Te Alloy Films," Journal of the Electrochemical Society, Vol. 140, No. 9, September 1993, pp. 2550-2553. doi:10.1149/1.2220860

[14] M. S. Martin-Gonzalez, A. L. Prieto, R. Gronsky, T. Sands and A. M. Stacy, "Insights into the Electrodeposition of $\mathrm{Bi}_{2} \mathrm{Te}_{3}$," Journal of the Electrochemical Society, Vol. 149, No. 11, November 2002, pp. C546-C554. doi:10.1149/1.1509459

[15] J. P. Fleurial, A. Borshchevsky, M. A. Ryan, W. M. Phillips, J. G. Snyder, T. Caillat, E. A. Kolawa, J. A. Herman, P. Mueller and M. Nicolet, "Development of Thick-Film Thermoelectric Microcoolers Using Electrochemical Deposition," Materials Research Society Symposium Proceedings, Vol. 545, 1999, pp. 493-500.

[16] S. Michel, S. Diliberto, C. Boulanger, N. Stein and J. M. Lecuire, "Galvanostatic and Potentiostatic Deposition of Bismuth Telluride Films from Nitric Acid Solution: Effect of Chemical and Electrochemical Parameters," Journal of Crystal Growth, Vol. 277, No. 1-4, April 2005, pp. 274-283. doi:10.1016/j.jcrysgro.2004.12.164

[17] H. M. A. Soliman and H. H. Abdel-Rahman, "The Use of Rotating Cylinder Electrode to Study the Effect of 1,3Dihydroxypropane on the Production of Copper Powder," Journal of the Brazilian Chemical Society, Vol. 17, No. 4, 2006, pp. 705-714. doi:10.1590/S0103-50532006000400011

[18] T. M. Tritt and M. A. Subramanian, "Thermoelectric Materials, Phenomena, and Applications: A Bird's Eye View," MRS Bulletin, Vol. 31, No. 3, March 2006, pp. 188-198. doi: $10.1557 / \mathrm{mrs} 2006.44$

[19] K. Tittes, A. Bund, W. Plieth, A. Bentien, S. Paschen, M. Plotner, H. Grafe and W. J. Fisher, "Electrochemical Deposition of $\mathrm{Bi}_{2} \mathrm{Te}_{3}$ for Thermoelectric Microdevices," Journal of Solid State Electrochemistry, Vol. 7, No. 10, May 2003, pp. 714-723. doi:10.1007/s10008-003-0378-8 